Doi: 10.5212/Uniletras.v.37i2.0004

\title{
QFWFQ E A ORIGEM DA LINGUAGEM E DO TEMPO OU A IMPOSSIBILIDADE DE FALAR SOZINHO
}

\section{QFWFQ AND THE ORIGIN OF LANGUAGE AND TIME OR INABILITY TO SPEAK ALONE}

Jeverson Nascimento

Silvana Oliveira**

Resumo: A proposta deste artigo é a análise de um dos contos de As Cosmicômicas, de Ítalo Calvino, intitulado "Um Sinal no espaço" à luz da teoria do discurso dialógico de Mikhail Bakhtin (1998/2003). A análise levará em conta, principalmente, a noção dialógica proposta por Bakhtin de que a existência do sujeito só ganha sentido a partir do seu contato com o outro pelo processo constante de diálogo promovido pelo uso da linguagem. No conto de Calvino somos apresentados a uma personagem em pleno processo de aquisição do signo e do código linguístico, o que o torna capaz de efetivar o contato com o outro responsivo e produtivo do diálogo no mundo da linguagem. Tal contato, como veremos, é carregado de uma potência modificadora de sentidos para ambos os participantes do jogo dialógico.

Palavras Chave: Cosmicômicas; Signo; Mikhail Bakhtin.

ABstract: The purpose of this article is the analysis of one of the tales of The Cosmicomics, by Italo Calvino entitled A Sign in space, in the light of the dialogical discourse theory of Mikhail Bakhtin (1998/2003). The analysis will take into account primarily the dialogical notion proposed by Bakhtin that the existence of the subject only makes sense from its contact with the other by the constant process of dialogue promoted by the use of language. In Calvino's story we are introduced to a character in the process of acquisition of the sign and the linguistic code, which makes it able to accomplish the contact with the other responsive and productive dialogue in the world of language. Such contact, as we shall see, is charged with a modifier power of senses for both participants in the dialogic game.

KEYwords: Cosmicômicas; Sign; Mikhail Bakhtin.

\footnotetext{
"Mestre em Linguagem pela UEPG - jeversonnascimento@gmail.com.

"Pós-doutoranda em Literatura Comparada pela UERJ, bolsista de Pós Doutorado Sênior da FAPERJ e professora associada do Departamento de Estudos da linguagem da UEPG - oliveira_silvana@hotmail.com.
} 


\section{INTRODUÇÃO}

O interesse em abordar uma obra da vasta produção do escritor italiano Italo Calvino (1923-1985) necessariamente passa pela compreensão do aspecto híbrido de seus escritos. Trata-se de um conjunto de textos que circula pelos campos da ficção, da filosofia, da crítica e da teoria literárias, sem que uma fronteira definitiva separe essas possibilidades criativas dentro de uma mesma composição.

Podemos afirmar que esse aspecto de sua produção é ainda mais marcante nos textos que se pretendem, a priori, como narrativas de ficção. É o caso, por exemplo, do famoso livro As Cidades Invisiveis (1972/1990) em que as narrativas do viajante Marco Polo ao imperador tártaro Kublai Kahn são, a um só tempo, o registro das possibilidades da observação humana, nas várias temáticas associadas às imagens múltiplas da cidade, e também uma reflexão profunda sobre o alento produzido pela linguagem frente ao desconcerto do mundo. Ao fim dos seus dias de conquista, "somente nos relatórios de Marco Polo, Kublai Kahn conseguia discernir, através das muralhas e das torres destinadas a desmoronar, a filigrama de um desenho tão fino a ponto de evitar a mordida dos cupins" (CALVINO, 1990, p. 10).

$O$ interesse de Kublai Kahn pelo relato de Marco Polo se justifica pela consciência de que apenas na compreensão de mundo capaz de ser expressa em palavras há alguma chance de vencer a vulnerabilidade de toda e qualquer glória no plano da experiência. Nessa percepção do sentido e dos efeitos da narrativa já está prevista uma das principais reflexões sobre a função da literatura, qual seja, a de dar permanência ao vivido e sentido à experiência.

Com a mesma característica de trazer questões teóricas sobre a literatura para o exercício criativo propriamente dito inscrevem-se outros textos do autor, tais como Se um viajante numa noite de inverno (1979), o Castelo dos destinos cruzados (1973), Palomar (1972), O Visconde Partido ao meio (1952), o Barão nas árvores (1957) e o Cavaleiro Inexistente (1959), os três últimos compõem a trilogia denominada pelo autor de "Nossos Antepassados".

Em Cosmicômicas (1965, originalmente; Cia. das Letras, 1992), a fiç̧ão também aparece como um discurso a provocar um outro, nesse caso, a ciência. Ao flertar com postulados científicos, ou pseudo-científicos, o autor articula os discursos da ficção e da ciência para promover a reflexão sobre os estatutos de verdade no mundo da física e da matéria. Novamente, assim como em As Cidades Invisiveis, a palavra ocupa o lugar de permanência para atribuir alguma estabilidade às verdades móveis do universo.

\section{As Cosmicômicas e a IRONIA CIENTífica}

Em As Cosmicômicas, Calvino apresenta uma série de contos que, por mais divergentes que se apresentem, trazem elementos comuns que permitem unificá-los em uma narrativa coesa. A começar pelo personagem principal de todas elas, um ser nomeado pelo palíndromo impronunciável Qfwfq, e a repetição de uma epígrafe de diferentes conotações científicas em todas as narrativas, de 
modo que se estabeleça um diálogo com o enredo do conto que vem em seguida.

A proposta deste artigo é a análise de um dos contos de As Cosmicômicas, de Ítalo Calvino, intitulado "Um Sinal no espaço", à luz da teoria do discurso dialógico de Mikhail Bakhtin (1998/2003). A análise levará em conta, principalmente, a noção dialógica proposta por Bakhtin de que a existência do sujeito só ganha sentido a partir do seu contato com o outro, pelo processo constante de diálogo promovido pelo uso da linguagem.

Cosmicômicas é um livro composto por ironias e metáforas, o que por si só já propõe um contraponto entre os discursos da ciência e da ficção literária. Cada conto traz uma premissa científica no epílogo e Calvino põem seu personagem Qwfwq a vivenciar uma estória contextualizada a partir da voz da ciência. Isso cria o efeito de o leitor perceber quando certas colocações trazidas pela ciência parecem incongruentes e até mesmo fantasiosas. Estamos, portanto, diante de uma contestação da lógica arbitrária e inquestionável do discurso científico. Além disso, cria-se o efeito literário de uma humanização do discurso científico, pois, por mais distante do humano que Qwfwq possa parecer, é com sensações humanas e a partir de sua subjetividade que as suas aventuras são vividas e narradas.

O conto "Um sinal no espaço" traz o seguinte epílogo: "Situado na zona externa da Via Láctea, o Sol leva cerca de duzentos milhões de anos para realizar uma revolução completa da Galáxia" (CALVINO, 1992, p.35). Logo na primeira frase que segue, e que efetivamente inicia o conto, já podemos perceber o efeito irônico, ao mesmo tempo humanizador do postulado científico antes citado:

Exatamente, este é o tempo que leva, nada menos, disse Qfwfq; eu uma vez passando fiz um sinal num ponto do espaço, de propósito, para poder vir a reencontrá-lo duzentos milhões de anos depois, quando viéssemos a passar por ali na volta seguinte. (CALVINO, 1992, p. 35).

A afirmação motivada pelo postulado científico expressa a resposta empírica dada por Qfwfq e que inicia com a palavra "exatamente", oposta ao advérbio "cerca" utilizada na premissa científica, que dá um caráter de incerteza quanto ao número apresentado. Essa relação é que caracteriza, a princípio, um efeito irônico do segundo texto em relação ao primeiro. O discurso científico utiliza-se de um subterfúgio para não se comprometer com a certeza, sendo então o texto literário, ficcional, que traz uma testemunha ocular que cronometrou o tempo e assim pode confirmar a premissa científica.

A forma como o pensamento bakhtiniano aborda a linguagem no romance nos ajuda a entender a relação construída em Cosmicômicas entre o discurso científico e o ficcional. Para Bakhtin:

A particularidade principal do estético, que diferencia nitidamente do conhecimento e do ato, é o seu caráter receptivo e positivamente acolhedor: a realidade, preexistente ao ato, identificada e avaliada pelo comportamento, entra na obra (mais precisamente no objeto estético) e torna-se então um elemento constitutivo indispensável. 
Nesse sentido, podemos dizer: de fato, a vida não se encontra só fora da arte, mas também nela, no seu interior, em toda a plenitude do seu peso axiológico: social, político, cognitivo ou outro que seja (BAKHTIN, 1998, p. 33).

Cosmicômicas utiliza-se da ciência para a construção artística, mas inverte seu peso axiológico ao produzir o efeito irônico. Podemos dizer que, nesse caso, a ficção brinca com a seriedade da ciência. No conto anotado aqui, o preceito científico é apresentado na epígrafe e em momento algum é negado, porém, ocorre uma cronometragem do tempo que o sol leva para percorrer a via-láctea, realizada empiricamente, coisa impossível para qualquer cientista que tenha calculado esse tempo. Assim, o narrador parece satirizar o discurso acadêmico, fazendo uma provocação aos cientistas ao revelar o caráter dedutivo do discurso da ciência frente à possibilidade de o discurso ficcional engendrar uma circunstância em que a prova do postulado da ciência seria absoluta.

Temos então que Ítalo Calvino utiliza uma estratégia discursiva chamada por Bakhtin de bivocalidade para criar o efeito cômico no texto:

A palavra desse discurso é uma palavra bivocal especial. Ela serve simultaneamente a dois locutores exprime ao mesmo tempo duas intenções diferentes: a intenção direta do personagem que fala e a intenção refrangida do autor. Nesse discurso há duas vozes, dois sentidos, duas expressões. Ademais, essas duas vozes estão dialogicamente correlacionadas, como que se se conhecessem uma à outra (como se duas réplicas de um diálogo se conhecessem e fossem construídas sobre esse conhecimento mútuo), como se conversassem entre si. O discurso bivocal sempre é internamente dialogizado. Assim é o discurso humorístico, irônico, paródico, assim é o discurso refratante do narrador, o discurso refratante nas falas dos personagens, finalmente, assim o discurso do gênero intercalado: todos são bivocais e internamente dialogizados. Neles se encontram um diálogo potencial, não desenvolvido, um diálogo concentrado de duas vozes, duas visões de mundo, duas linguagens. (BAKHTIN, 1998, 127-128)

$\mathrm{Na}$ constituição do discurso de "Um sinal no espaço", ao mesmo tempo em que o narrador dialoga com o discurso científico, mantendo-o como referência na narrativa ficcional, ele refrata a intenção do autor, que é, como falamos acima, ironizar a falsa objetividade e a não humanização do discurso científico.

\section{O HERÓI, O SIGNO E O OUTRO}

Certamente Qfwfq é um personagem peculiar na história da literatura. Não só devido ao seu nome impronunciável (similar à representação de uma equação ou fórmula, composto de forma palíndroma, pois o inverso da estranha palavra mantém a mesma ordem), mas também por se tratar de um ente que surgiu junto com o universo, e, além disso, participou ativamente de muitos eventos que o constituíram, como o Big Bang, a extinção dos dinossauros e a origem dos signos

É difícil definir esse Adão sígnico. Um ente com consciência humana, mas que tem 
poderes que extrapolam os limites humanos, evidenciados pela sua relação com o universo que o rodeia. Um ser que pode colocar o braço para fora da via láctea para marcar um signo.

É interessante pensar que é com o princípio da construção sígnica, o elementar da linguagem, que Qfwfq percebe que não está só no universo. No conto "Um sinal no espaço" quanto Qwfwq faz um signo no universo ele se dá conta da existência de outro personagem, que lhe copia os gestos, lhe responde e lhe dá a certeza de que já não está mais sozinho. Podemos entender a atitude responsiva de Kgwgk como necessária, pois, apesar de Qfwfq encontrar-se só e traçar seu signo para uma atividade unicamente funcional, como sujeito que deixa uma marca, ele precisa ser necessariamente respondido, precisa de um interlocutor. Segundo Bakhtin (2003, p.272) "toda compreensão plena real é ativamente responsiva".

É a construção signa de Qfwfq que permite a Kgwgk se expressar, borrando e copiando o primeiro signo, o que se configura como uma resposta interlocutiva que dá a Qfwfq a possibilidade de não mais se encontrar só no universo. Essa descoberta do outro traz um sentido para a consciência que o herói tem de sua subjetividade, a relação que ele passa a ter com o universo após esses eventos torna-se, processualmente, múltipla e complexa:

Mas com o passar dos anos galácticos o espaço já não era aquela extensão uniformemente árida e pálida, A ideia de marcar com sinais os pontos por onde se passava, assim como tinha vindo a mim e a Kgwgk, viera a muitos outros, espalhados por milhares de planetas de outros sistemas solares, e continuamente me defrontava com um desses tais, ou um par deles, ou sem mais nem menos com uma dúzia, simples garatujas bidimensionais, ou às vezes sólidos em três dimensões (por exemplo, poliedros), e também até com coisas feitas com mais capricho, em quatro dimensões e tudo. A verdade é que chego ao lugar do meu sinal e ali encontro cinco, todos juntos. E não me vejo em condições de reconhecer o meu. É este, não, é aquele outro, qual!, este tem um ar demasiadamente moderno e, no entanto, poderia ser o mais antigo, aqui não reconheço a minha mão, imaginem se me viria a mente fazê-lo dessa forma... E enquanto isso a Galáxia corria pelo espaço deixando atrás de si os velhos sinais e os sinais novos e eu ficava sem encontrar o meu (CALVINO, 1992, p. 43).

Após o início da disputa com Kgwgk, além de ansiedade, Qfwfq passa a sentir vergonha, inveja, enfim, sua existência também começa a se complexificar pelo contato com um outro responsivo e problematizador da sua própria existência. A relação com o outro potencializa a compreensão profunda do eu; em termos bakhtinianos, temos que

O conjunto da minha vida não tem significação no contexto axiológico de minha vida. Os acontecimentos do meu nascimento, da minha permanência axiológica no mundo e, por último, de minha morte não se realizam em mim nem para mim. O peso emocional de minha vida em seu conjunto não existe para mim mesmo. 
Os valores de uma pessoa qualitativamente definida são inerentes apenas ao outro. Só com ele é possível para mim a alegria do encontro, a permanência com ele, a tristeza da separação, a dor da perda, posso encontrar-me com ele no tempo e o tempo mesmo separar-me dele, só ele pode ser e não ser para mim (BAKHTIN, 2003, p.96)

Assim, antes da construção sígnica que possibilitou a relação com outro, Qfwfq podia até existir e ter uma consciência, mas não poderia se ver como sujeito, não poderia ter consciência de si mesmo. Não é à toa que sua narrativa em primeira pessoa inicia exatamente no momento em que traça seu signo.

É claro que o personagem tracejou seu signo para cronometrar o tempo que o sistema solar levaria para dar um volta na via - láctea. No entanto, esse é só mais um elemento que evidencia que a linguagem e o outro são elementos essenciais na constituição subjetiva, seja ela estética ou não, já que para dizer-se a si mesmo e receber a resposta do outro é preciso um código expressivo que carrega as intencionalidades de modo compartilhado.

\section{A INVENÇÃO DO TEMPO}

O tempo é um elemento que permanece em constantes discussões nas mais diversas áreas do conhecimento. As infinitas possibilidades de compreender o tempo alimenta e alimentou mitologias e devaneios místicos, religiosos e/ou filosóficos das mais diferentes formas e por todo o mundo.

Qfwfq parece ser imune à passagem do tempo. Em Cosmicômicas ele participa de eventos que vão deste o Big Bang até a extinção dos dinossauros. No conto "Um sinal no espaço o personagem se refere a milhões de anos como se fossem dias. Se tomarmos o conceito de tempo da história de Umberto Eco (1994) teremos o registro da passagem de algumas centenas de milhões de anos neste único conto.

A partir da criação do signo, Qfwfq começa a ter uma relação diferenciada com o tempo, que passa a ser percebido mais subjetivamente, principalmente devido a sua ansiedade:

Um dia após o outro, já agora devia estar próximo. Fremia de impaciência porque podia chocar-me com o sinal a cada instante. Era aqui, não, um pouco mais a frente, e agora conto até cem... E se não estivesse? Se já o tivesse passado? Nada. Meu sinal permanecia sabe-se lá onde, para trás, completamente fora de mão relativa à órbita de revolução do nosso sistema. Não havia contado com as oscilações a que, mormente naqueles tempos, eram sujeitas as forças de gravidade dos corpos celestes e que os levavam a desenhar órbitas irregulares e recortadas como flores de dália. Por uma centena de milênios atormentei-me a refazer meus cálculos; decorreu que nosso percurso atingia aquele ponto não a cada ano galáctico, mas apenas a cada três, ou seja, a cada seiscentos milhões de anos solares. Quem havia esperado duzentos milhões de anos bem podia esperar mais seiscentos; e esperei, o caminho era longo, mas enfim não o devia fazer a pé; na garupa da galáxia percorria os anos-luz corcoveando sobre órbitas planetárias e estelares como na sela de um cavalo cujos cascos esguichassem 
centelhas; e encontrava-me num estado de exaltação cada vez mais crescente; parecia avançar para a conquista da única coisa que contava para mim, sinal e reino e nome... (CALVINO, 1992, p.39)

Qfwfq dá a entender que já conhecia a contagem do tempo, principalmente os anos, porém é a partir da criação signa que o tempo passa a fazer um sentido para ele, passa a ter uma conotação subjetiva. Ao tornar-se um sujeito de linguagem, capaz de representar a si mesmo e ao outro, Qfwfq passa a experimentar a angústia da passagem do tempo.

Essa utilização do signo relacionado diretamente à passagem do tempo vem já de algum tempo na filosofia. Santo Agostinho, já no século $V$ da era cristã fazia essa relação. Após discorrer sobre a ontologia do tempo ele faz um experimento linguístico para ilustrar suas colocações:

Este verso Deus Creator omnium, de oito sílabas, vai-se alternando com sílabas breves e longas. Quatro breves: a primeira, terceira, quinta e sétima. Estas são simples comparadas com as quatro longas: a segunda, quarta, sexta e oitava. Cada uma destas tem o dobro de tempo em relação às outras. Assim o noto pelo testemunho dos sentidos (AGOSTINHO, 2000, p.292).

E continua:

Em ti, ó meu espírito, meço os tempos! Não queiras atormentar-me, pois assim é. Não te perturbes com os tumultos das tuas emoções. Em ti, repito, meço os tempos. Meço a impressão que as coisas gravam em ti à sua passagem, impressão que permanece, ainda depois de elas terem passado. Meço-as, a ela enquanto é presente, e não àquelas coisas que se sucederam para a impressão ser produzida. É a essa impressão ou percepção que eu meço, quando meço os tempos (AGOSTINHO, 2000, p. 292).

Apesar de Agostinho vir de uma escola de pensamento platônica, para a qual o tempo era a medida do movimento das coisas e dos seres, ele parece negar essa concepção, por isso utiliza um exemplo intangível e subjetivo, a pronúncia das palavras. Assim é também a percepção do tempo para Qfwfq, a partir do momento em que ele se constitui simbolicamente, acionando a ação do signo na conformação de uma linguagem capaz de colocá-lo em contato com o outro.

Em "Um sinal no espaço", a incompletudo do herói é dada pela sua consciência de ser um ente no tempo. Qfwfq sente-se inquieto, perde-se nas voltas pelas galáxias e nas contas dos anos, sua expectativa pela passagem do tempo e pelo porvir dos eventos lhe colocam na dimensão humana de não controlar $o$ anel de sua existência.

Seu pensamento e sua existência só fazem sentido no signo a ser encontrado, ou seja, no futuro. Sua existência só volta então a ter sentido quando reencontra seu signo, pois aí ele percebe a existência de outro ser. Somente quando Kgwgk borra seu símbolo, interferindo assim no sentido original atribuído a ele, é que Qfwfq assume outras preocupações que não a ansiedade e os cálculos temporais exclusivos para reencontrar seu signo. O outro se inscreve na ação expressiva 
de Qfwfq, de modo a respondê-la e iniciar um processo dialógico ativo entre as duas figuras. Essa conformação dialógica é também analisada por Bakhtin em sua filosofia, que trabalha exaustivamente a relação estabelecida entre o eu e o outro nos processos de interação. Interessa para nós nesse momento a reflexão bakhtiniana sobre as prerrogativas temporais:

Em mim mesmo vivo sempre diante de uma exigência-objetivo absoluta que me é colocada, e de mim para ela não pode haver uma aproximação gradual, parcial e relativa. Eis a exigência: vive como se cada momento dado de tua vida pudesse ser o conclusivo e último, mas, ao mesmo tempo, também o momento inicial de uma nova vida; essa exigência é para mim irrealizável por princípio, porque nela a categoria estética (a relação com o outro) ainda continua viva, mesmo que enfraquecida. Para mim mesmo, nenhum momento pode tornar-se auto-suficiente a ponto de conscientizar-se axiologicamente de si mesmo como conclusão justificada de toda a vida e digno de começo de outra nova. (...) (BAKHTIN, 2003, p.111-112).

Assim, podemos compreender a mudança de postura de Qfwfq após a descoberta de seu opositor no bosquejar dos signos. A aflição em encontrar seu signo transforma-se em disputa com Kgwgk, o que revigora sua narrativa, pois seu mundo, assim como sua existência, passa a ter um novo sentido. A expectativa pela passagem do tempo e o porvir dos eventos é alterada e intensificada pela interferência responsiva e ativa de um outro ente capaz de expressar-se e fazer da experiência uma atividade de interação. Todo um mundo pode alterar-se pela simples presença de um outro ente que olha e dá sentido ao que vê, em uma atividade significativa exterior inédita para Qfwfq:

Num ponto que deveria ser exatamente aquele ponto, em lugar do meu sinal havia um esfregaço informe, uma abrasão do espaço, deteriorada e carcomida. Perdera tudo: o sinal, o ponto, aquilo que fazia com que eu - sendo autor daquele sinal naquele ponto - fosse de fato eu. O espaço, sem sinal, tornara-se uma voragem de vácuo sem princípio nem fim, nauseante, na qual tudo - eu inclusive - se perdia.

(...)

Mas, naquele momento, o desejo de não admitir a vitória de meu rival prevaleceu em mim acima de qualquer oura consideração: quis logo traçar um novo sinal no espaço que representasse um verdadeiro sinal e fizesse Kgwgk morrer de inveja. (Calvino, 1992, p. 39-40)

Ou seja, antes do aparecer de Kgwgk, Qfwfq vivia no futuro, no ainda porvir, o sentido de sua existência está no sinal que não reencontra. No entanto, é com a realização desse momento tão esperado que ocorre o surgimento de um outro, o que o faz voltar ao presente de sua existência, o que o desestabiliza e lhe permite se reorganizar no tempo e no espaço a fim de enfrentar seu opositor, uma realidade possível também somente no porvir. Trata-se, como se vê, de uma atualização de expectativas em resposta à atuação do outro em sua vida. Assim, é a visão excedente 
que tem do outro que organiza seu tempo, e faz com que sua própria vida tenha um novo sentido. Novamente recorremos a Bakhtin para aprofundar a compreensão dos efeitos de sentido da narrativa de Calvino:

O outro está mais intimamente ligado ao tempo (não se trata, claro, do tempo elaborado pela matemática nem pelas ciências naturais, pois isto subentenderia uma generalização correspondente do homem), está por inteiro inserido no tempo como o está inteiramente no espaço, no vivenciamento dele por mim nada perturba a temporalidade contínua de sua existência. Eu não estou para mim mesmo inteiramente no tempo, mas "minha maior parte" é vivenciada intuitivamente por minha própria pessoa fora do tempo, eu disponho de um apoio imediatamente dado no sentido (...). É claro, ainda, que eu não disponho de minha vida, de meu pensamento, de meus atos, que não os organizo no tempo (um certo todo temporal) - o horário de um dia evidentemente não organiza a vida - mas, antes, de forma sistemática; em todo o caso trata-se de uma organização dos sentidos (...); eu não vivo o aspecto temporal de minha vida, ela não é o princípio diretivo nem o ato prático elementar; o tempo é técnico para mim, como técnico é o espaço (eu domino a técnica do tempo e do espaço). Eu organizo essencialmente a vida do outro concreto e definido no tempo - onde eu, evidentemente, não abstraio seus afazeres de sua personalidade -, não num tempo cronológico nem matemático, mas no tempo emotivo-axiológico ponderável da vida, capaz de tornar-se rítmico-músical. (BAKHTIN, 2003, 100)

Partindo da citação acima, podemos entender como o texto de Calvino cria uma situação em que a existência de Qfwfq só faz sentido a partir de sua relação com o tempo, com o outro por meio da construção signíca na perspectiva dialógica da construção de um código compartilhado.

\section{ConClusão}

Propomos a associação do pensamento bakhtiniano à composição de Italo Calvino com a intenção de esclarecer mutuamente os dois textos, de forma a compreendê-los como dicções diferentes de um mesmo ponto de vista sobre a importância do signo, num plano geral, no processo de interação humano; e da linguagem, num plano mais específico, no que tange às possibilidades dialógicas definidoras da existência dos seres no jogo interativo do mundo.

Umberto Eco (2005), nos seus passeios pelo bosque da ficção nos dá uma série de exemplos de leitores de seus romances que foram felizes e infelizes ao proporem certas analogias e alusões a seus textos ficcionais. Por fim conclui que "Entender o processo criativo é entender também como certas soluções textuais surgem por acaso, ou em decorrência de mecanismos inconscientes" (p. 100). Não se trata então de identificar a influência de um texto sobre outro, ou de um autor sobre outro. O que cabe ressaltar é a perspicácia do pensamento de Mikhail Bakhtin no entendimento das relações vida/ literatura, bem como a habilidade discursiva 
de Italo Calvino na composição de um mundo em que o signo e a linguagem nascem para efetivar a experiência dialógica inerente aos processos de interação.

\section{REFERÊNCIAS}

AGOSTINHO. Confissões. Petrópolis: Vozes, $15^{\mathrm{a}}$ ed. 2000.

BAKHTIN, M. Estética da criação verbal. Tradução de Paulo Bezerra $4^{\mathrm{a} e d . ~ S a ̃ o ~ P a u l o: ~}$ Martins Fontes, 2003.

Questões de literatura e estética: A teoria do romance. Tradução de Aurora Fornoni Bernardini e outros. São Paulo: UNESP. 1998. CALVINO, Í. As cosmicômicas. Tradução de Ivo Barroso. São Paulo: Companhia das letras, 1992. ECO, U. Interpretação e superinterpretação. São Paulo: Martins Fontes. 2005 . Seis passeios pelos bosques da ficção.

São Paulo: Companhia das Letras. 1994.

Recebido para publicação em 02 nov. 2015

Aceito para publicação em 20 abril 2016. 